\title{
Top 3 Differentials in Pediatric Radiology: A Case Review - Rebecca Stein-Wexler (ed)
}

\author{
Published by Thieme Medical Publishers Inc., New York, USA; 2019; ISBN: 978-1-62623-370-6; \\ Pages: 410
}

\section{Manisha Jana ${ }^{1}$}

Received: 4 June 2019 / Accepted: 12 July 2019 / Published online: 24 July 2019

(C) Dr. K C Chaudhuri Foundation 2019

This book, titled 'Top 3 Differentials in Pediatric Radiology: A Case Review' by Rebecca Stein-Wexler encompasses common cases and pathology encountered in daily practice in pediatric radiology. This book includes 194 cases of different organ-systems divided in 6 sections. Each case is packed with brief and high-yield discussion regarding top differential diagnoses for the key imaging findings. The illustrations are of good quality. Imaging pearls are provided at the end of each case to allow for a quick review of key teaching points with a concise list of relevant references for the reader seeking a deeper understanding of the entity. To make the search for any specific entity easier, an index of imaging findings is provided at the end of the book.
The book is very informative, concise and quick to read. However, as this is not a complete textbook in itself, further reading of the entities described is encouraged. There are very few radiographs of acute chest emergencies/ ICU radiographs. Also, in the neurology section, a few more cases of leukodystrophies would have been more useful to the readers.

In a nutshell, this is a power packed illustrative review of pediatric radiology for the radiology trainees. Also, equally useful for the residents in Pediatrics.

Publisher's Note Springer Nature remains neutral with regard to jurisdictional claims in published maps and institutional affiliations.
Manisha Jana

manishajana@gmail.com

1 Department of Radiodiagnosis, All India Institute of Medical Sciences, New Delhi 110029, India 